\title{
LA IGUALDAD DE DERECHOS DEL HOMBRE Y LA MUJER EN EL CODIGO CIVIL VIGENTE Y EL PROYECTO
}

Ricardo Marcenaro Frers

La historia puede ser estudiada y analizada desde diferentes perspectivas. Quizás una de las características más constantes en la evolución humana es el de la dominación. Siempre han existido grupos de personas dominando a otros por razones de raza, religión, poder económico, etc. Estas formas de dominio se fundamentan en teorias $y$ argumentaciones que atribuyeron su razón de ser a la divinidad o a la naturaleza humana. De esta manera grupos religiosos sometieron por la fuerza a los no creyentes toda vez que sólo los dominantes eran poseedores del mensaje divino. Solo ellos habían sido favorecidos con la fe en el verdadero Dios y por lo tanto tenian el derecho de someter a aquellos que no participaban de las mismas creencias. En otros momentos de la evolución humana se ha establecido el pleno dominio de una raza sobre otras basado en la supuesta superioridad de aquella. También se establece el dominio de los grupos que cuentan con todo el poder económico fundado en una capacidad y habilidad especial atribuible a la naturaleza humana. 
Las formas de dominación han sido vencidas por los oprimidos con el transcurrir de los años y en mérito a la necesidad de libertad e igualdad del ser humano.

Consideramos que de todas las formas de dominación la que resulta más dificil de vencer es la de supremacia del hombre sobre la mujer. Es la forma de dominación en la que mayor resistencia se ha opuesto para evitar su eliminación. Los argumentos para mantener el dominio de un sexo sobre el otro han sido diversos. Se ha sostenido que Dios ha establecido dicha dominación o que la propia naturaleza la ha determinado.

Con carácter ilustrativo transcribimos a continuación lo expresado por el Dr. José M. Aranibar, en su obra Derecho Civil Peruano. Tomo I, que obtuvo el Primer Premio en el concurso Procultura Juridica correspondiente a 1967 convocada por el Colegio de Abogados de Arequipa. "Es indudable que entre el varón y la mujer existen diferencias orgánicas y psíquicas que han sido y son la causa de que al primero, se le considere más apto que a la segunda para desempeñar el rol que les incumbe en la actividad social por más que algunos se empeñan en establecer la igualdad psíquica de ambos sexos, ya que la orgánica seria imposible concebirla... El feminismo exagerado, presuncioso y extremista que trata de igualar en todo sentido a las personas de ambos sexos, hasta el punto de emancipar completamente a la mujer de la Autoridad Marital y de la patria potestad de los padres, nos parece inaceptable e intelorable porque desquicia el hogar, es cacusa de abandono de los hijos, fomenta el libertinaje y trae como resultado la destrucción de la familia y el desafecto de la nacionalidad". Hoy en dia es sorprendente constatar el gran número de personas de ambos sexos que participan de estas ideas. Ante el Derecho todas las personas deben ser iguales y por lo tanto gozar de los mismos derechos y estar sujetos a identicas obligaciones, la única diferencia es la establecida para proteger a los incapaces. Las leyes otorgaban a las mujeres la categoria de incapaces relativas y por ello no es de extrañar que recién mediante Ley 12391 del 7 de setiembre de 1955 se reformó la Constitución y se les otorgó el derecho al sufragio sin restricciones. Es evidente que existen diferencias físicas y psiquicas entre el hombre y la mujer pero estas no determinan una 
mayor capacidad juridica. Las diferencias de derechos señaladcs por los autores se basan en razones culturales y no jurídicas.

La Constitución señala en su Art. II que toda persona tiene derecho a la igualdad ante la ley, sin discriminación alguna por razón de sexo. Luego añade que el varón y la mujer tienen iguales oportunidades y responsabilidades. A pesar de que se indica expresamente que el varón y la mujer son iguales ante la ley luego agrega "La ley reconoce a la mujer derechos no menores que al varón". En consecuencia puede tener derechos mayores y asi los establece:

a. - "La madre tiene derecho a la protección del Estado y a su asistencia en caso de desamparo" Art. 7 .

b. - La ley "Determina las condiciones del trabajo de menores y mujeres" Art. 44.

c.- "La ley determina las medidas de protección a la madre trabajadora" Art. 45.

Por las razones expuestas podemos concluir que a pesar que la Constitución señala la igualdad del varón y la mujer luego se contradice al establecer que ésta podrá gozar de derechos mayores. Si goza de mayores derechos no existe igualdad.

No obstante el comentario anterior consideramos que señalar expresamente entre los derechos fundamentales de la persona "A la igualdad ante la ley, sin discriminación alguna por razón de sexo..." (Art. 2) es la reforma constitucional más significativa.

El proyecto del Código Civil ha adoptado este mismo criterio con lo que se extrae a la mujer, por lo menos en la Legislación, de la situación milenaria de considerarla como sujeto con incapacidad relativa.

Puede notarse claramente el cambio trascendental que ofrece el Proyecto del Código Civil si transcribimos a continuación los Artículos concordados con el Código Civil vigente: 
Código Civil. Art. 24 "La mujer casada tiene por domicilio el de su marido".

Código Civil. Art. 162 "Al marido compete fijar y mudar el domicilio de la familia..."

PROYECTO ART. 145 "El domicilio de los connyuges que hagan vida en común será el que fijen de mutuo acuerdo ya sea expresa o tácitamente".

Código Civil. Art. 161 "El marido dirige la Sociedad Conyugal. La mujer debe al marido ayuda y consejo para la prosperidad común y tiene el derecho y el deber de atender personalmente el hogar".

PROYECTO ART. 338 "Ambos cónyuges tienen el deber y el derecho de participar, según sus posibilidades y capacidades, en el Gobierno del hogar y cooperar al mejor desevolvimiento del mismo".

PROYECTO ART. 283 "El marido y la mujer tienen en el hogar Autoridad, consideraciones, derechos, deberes y responsabilidades iguales".

Código Civil. Art. 164 "El marido está obligado a suministrar a la mujer, y en general a la familia, todo lo necesario para la vida, según sus facultades y situación".

PROYECTO ART. 339 "Los cónyuges están obligados a contribuir al sostenimiento del hogar según su capacidad económica. No obstante si uno de ellos se dedicara exclusivamente al trabajo del hogar y al cuidado de los hijos, la obligación de sostener a la familia recae sobre el otro, sin perjuicio de la ayuda y colaboración que ambos cónyuges se deben en uno y otro campo".

Código Civil. Art. 168 "El marido es el representante de la Sociedad Conyugal".

PROYECTO ART. 340 "Corresponde conjuntamente a ambos cónyuges la representación legal de la Sociedad Conyugal". 
Código Civil. Art. 173 "La mujer puede ejercer cualquier profesión o industria, asi como efectuar cualquier trabajo fuera de la casa común con el consentimiento expreso o tácito del marido".

PROYECTO ART. 341 "Cada cónyuge puede ejercer cualquier profesión o industria permitidos por la ley, asi como efectuar cualquier trabajo fuera del hogar con el consentimiento expreso o tácito del otro".

Código Civil. Art. 171 "La mujer lleva el apellido del marido, agregado el suyo, y lo conserva mientras no contraiga nuevo matrimonio".

PROYECTO ART. 128 "El matrimonio permite a la mujer llevar el apellido paterno de su marido agregado al suyo..."

Código Civil. Art. 391 "La patria potestad se ejerce por el padre y la madre durante el matrimonio. En caso de disentimiento prevalecerá la opinión del padre".

PROYECTO ART. 187 "La patria potestad se ejerce conjuntamente por el padre y la madre, corresponde a ambos la representación legal del hijo y la administración de sus bienes".

Hasta el momento hemos presentado una breve exposición acerca de las favorables transformaciones que refleja el Proyecto del Código Civil. Sin embargo solamente significará un cambio adecuado en la Legislación. Esto no implica que nuestra población peruana esté dispuesta al cambio y que todos comparten la convicción de que el varón y la mujer tienen los mismos derechos.

Es inobjetable la constatación de que en nuestra realidad se dan grandes desigualdades entre el varón y la mujer ante el Derecho, la familia y la Sociedad. Tampoco es posible considerar a la Sociedad Peruana como una sola por cuanto encontraremos muchas distinciones de acuerdo al estrato social, nivel cultural, lugar de residencia (rural o urbana) etc. En consecuencia no podemos hablar del varón o la mujer peruanos por cuanto las caracteristicas dependerán del grupo al que nos referimos. Es 
totalmente diferente el rol que cumple en la familia y la Sociedad el ama de casa de Lima con relación a la mujer de las comunidades campesinas, de las comunidades selvicolas o la de los pueblos jóvenes de las zonas urbanas.

Deseamos presentar a continuación algunos datos del censo de población efectuado en julio de 1981 que permitirá señalar en cifras la gran diferencia que existe entre el varón y la mujer. Solamente indicaremos los porcentajes en que participan los varones y mujeres del total de personas consignadas en dichos rubros.

\section{VARONES MUJERES}

1.-Población total

$49.8 \%$

$50.2 \%$

2.-Con educación completa superior universitaria.

$61.7 \%$

$38.3 \%$

3. -No sabe leer y escribir.

$36.3 \%$

$63.7 \%$

4.-Población económicamente activa.

$74.5 \%$

$25.5 \%$

5.-Ocupados.

$75.3 \%$

$24.7 \%$

6.-Población no económicamente activa.

7.-Quehaceres del hogar.

$3 \%$

$97 \%$

8.-Servicios domésticos.

$15.5 \%$

$84.5 \%$

9.-Profesionales, técnicos y trabajadores asimilados.

$62.9 \%$

$37.1 \%$

10.-Funcionarios públicos superiores, Gerentes de empresas.

$92.1 \%$

$7.9 \%$

11. Promedios de ingresos.

$\mathrm{S} / .60,000$

S/. 49,000

Es significativo señalar que de todos los comentarios efectuados por Juristas sobre el Proyecto del Código Civil ninguno que hayamos leido menciona a la igualdad del varón y la mujer como el cambio más adecuado. 
Consideramos que la innovación más trascendente y significativa es establecer las normas de convivencia que proyecten la total igualdad de los integrantes de ambos sexos. Sin embargo esta paridad ante la ley no implicará necesariamente igualdad real. Existen en nuestra cultura muchísimos factores que for mentan la diferencia de derechos de los sexos y no será suficiente que se promulguen las normas legales que reflejen la igualdad del varón y la mujer para que ésta se dé de hecho sino que será preciso iniciar una intensa labor de difusión cultural que permita a nuestra población internalizar estos conceptos. 